\title{
Growth and cultural characteristics of Calymmatobacterium granulomatis - the aetiological agent of granuloma inguinale (Donovanosis)
}

\author{
A. B. M. KHARSANY, A. A. HOOSEN, P. KIEPIELA, T. NAICKER* and A. W. STURM \\ Department of Medical Microbiology and *Electron Microscope Unit, Faculty of Medicine, University of Natal, \\ Durban, South Africa
}

Granuloma inguinale is a chronic destructive granulomatous disease of the genitalia. The clinical diagnosis is often unreliable and the definitive diagnosis is based on the visualisation of 'Donovan bodies' in tissue smears or biopsy specimens. The organism implicated in its aetiology, Calymmatobacterium granulomatis, was reported to have been cultured $>\mathbf{3 0}$ years ago, but little is known about the organism because of its fastidious nature and the difficulty in culturing it. Twenty-two biopsy specimens from female patients with clinical and laboratory-confirmed granuloma inguinale were treated with amikacin $10 \mathrm{mg} / \mathrm{L}$ and inoculated in a monocyte co-culture system with peripheral blood mononuclear cells (PBMC) from a single donor and autologous sera. The method was subsequently modified by pretreatment of specimens with vancomycin $5 \mathrm{mg} / \mathrm{L}$ and metronidazole $10 \mathrm{mg} / \mathrm{L}$ in addition to amikacin $10 \mathrm{mg} / \mathrm{L}$ for the purpose of decontamination, pooled blood donor PBMC and by the use of heat-inactivated fetal calf serum instead of autologous serum for culture. This modified method was used to culture additional biopsy specimens and genital ulcer scrapings from female and male patients, respectively. All monocyte co-cultures were examined by a rapid Giemsa (RapiDiff) stain and by an indirect immunofluorescence test with immune sera. Representative cultures were examined by transmission electron microscopy. $C$. granulomatis was successfully isolated in pure culture by the monocyte co-culture system from four biopsy specimens and 14 genital ulcer scrapings. The cultured organisms were visible both intra- and extra-cellularly and were extremely pleomorphic, with characteristic single and bipolar condensation. The numbers of the organisms increased after each passage. All positive cultures showed bright fluorescence when tested with immune sera. Transmission electron microscopy of the cultured bacteria demonstrated a typical gram-negative cell wall consisting of an outer membrane, middle electron opaque layer and an inner plasma membrane. The capsule was thick and electron dense. Numerous electron dense granules were present within the cytoplasm.

\section{Introduction}

Granuloma inguinale, also known as Donovanosis, is a chronic granulomatous disease involving the genitalia and surrounding sites. It is found in specific geographical foci, namely New Guinea, north western Australia, south-east India, the Caribbean, parts of South America, parts of central Africa [1] and the KwaZulu/Natal region of South Africa [2].

In 1905, Donovan first described the characteristic intracytoplasmic inclusion bodies in mononuclear cells which were present in smears from oral lesions of a

Received 22 Aug. 1996; accepted 11 Nov. 1996. Corresponding author: Dr A. B. M. Kharsany. patient who also had ulcerated lesions of the genitalia [3]. These were recognised as the aetiological agent and named Calymmatobacterium granulomatis [4]. Currently the laboratory diagnosis of granuloma inguinale relies on the observation of 'Donovan bodies' in tissue smears or biopsy specimens examined by Giemsa and Wright stains [5]. To increase the sensitivity and specificity of the diagnosis, Dieterlies, Warthin-Starry [6] and the rapid Giemsa (RapiDiff) [7] stains have been used.

No real progress has been made with regard to culture of the aetiological agent. In 1943, Anderson [8] reported growth of a gram-negative capsulate bacillus in the yolk of embryonated eggs from a tissue specimen rich in Donovan bodies. Thereafter, between 1943 and 1951, several reports on the primary isolation 
of the micro-organism in the yolk sac of embryonated eggs [9-12] and chick brain [13] appeared and a few of these cultures were reported to have adapted to growth on cell-free media such as the fresh yolk medium of Dienst et al. [12] and Locke-yolk medium of Dulaney et al. [14]. The fresh yolk medium of Dienst et al. [12] was modified by replacing the egg yolk with lactalbumin hydrolysate and Anderson's originally passaged strain was said to have been cultured in 1959 [15]. Sodium azide and brilliant green were added to this medium to make it selective and in 1962 Goldberg reported the isolation of an organism resembling $C$. granulomatis from the faeces of a patient with cervical granuloma inguinale [16].

Despite the reports of these early successes, there has been no subsequent publication on the growth or nature of the organism or its susceptibility to antimicrobial agents. Furthermore, no strains are available from any type culture collection worldwide. Recently, the successful growth of $C$. granulomatis in a monocyte co-culture system from biopsy specimens of three patients with ulcerative lesions was reported [17]. The present study reports on the modification of this coculture technique and its application in the growth of the organism from tissue scrapings of genital lesions.

\section{Materials and methods}

\section{Development of co-culture system}

Over a 3-year period from Jan. 1993 to Dec. 1995, all female patients with ulcerative genital lesions presenting to the antenatal and gynaecology outpatient clinics of King Edward VIII Hospital, Durban, were investigated. Smears or tissue biopsy specimens, or both, were obtained from ulcerative lesions and investigated for chancroid, herpes genitalis, lymphogranuloma venereum, syphilis and granuloma inguinale by conventional laboratory tests. All 'Donovan body'-positive biopsy specimens were processed for co-culture in monocytes.

To obtain peripheral blood mononuclear cells (PBMC), $30 \mathrm{ml}$ of peripheral blood were obtained from a single normal healthy volunteer. This was mixed with an equal volume of Hanks's Balanced Salts Solution (HBSS; Whittaker M. A. Bioproducts, MD, USA) and passed through density gradient centrifugation with Histopaque 1077 (Sigma). The PBMC collected from the interface were rinsed in HBSS and suspended in RPMI 1640 (Whittaker M. A. Bioproducts) supplemented with $2 \mathrm{mML}$-glutamine and unheated autologous serum $10 \%$. The cells were transferred to tract vials containing glass coverslips (Bibby Sterilin) to allow monocyte adherence for $1 \mathrm{~h}$ at $37^{\circ} \mathrm{C}$ in $\mathrm{CO}_{2} 5 \%$ in air. Each vial was then washed free of non-adherent cells with supplemented RPMI 1640 medium. The viability (99\%) of PBMC was assessed with the trypan blue stain.

Biopsy specimens were suspended in supplemented RPMI 1640 and treated with amikacin (Bristol Laboratories) at a concentration of $10 \mathrm{mg} / \mathrm{L}$ for $2 \mathrm{~h}$ to eliminate contaminating bacteria, and then rinsed in $\mathrm{PBS}, \mathrm{pH} 7.2$, homogenised with a Dounce tissue grinder and resuspended in supplemented RPMI 1640. Each specimen $(500 \mu \mathrm{l})$ was inoculated into three vials of monocytes. The vials were incubated for $1 \mathrm{~h}$ at $37^{\circ} \mathrm{C}$ in $\mathrm{CO}_{2} 5 \%$ in air and $1 \mathrm{ml}$ of fresh supplemented RPMI 1640 was added, followed by incubation for a further $48 \mathrm{~h}$. Subcultures were made on to a fresh monocyte monolayer. In order to check for contaminating flora (Table 1) and to determine whether any cell-free media would support the growth of C. granulomatis (Table 2),

Table 1. Culture media and incubation conditions used to check monocyte cultures for the presence of contaminating flora

\begin{tabular}{ll}
\hline Medium & $\begin{array}{l}\text { Incubation } \\
\text { temperature }\end{array}$ \\
\hline Blood agar & $25^{\circ} \mathrm{C}, 33^{\circ} \mathrm{C}, 37^{\circ} \mathrm{C}$ \\
MacConkey agar & $37^{\circ} \mathrm{C}$ \\
Chocolate agar & $37^{\circ} \mathrm{C}$ \\
Sabouraud's agar & $25^{\circ} \mathrm{C}, 37^{\circ} \mathrm{C}$ \\
Brucella agar & $25^{\circ} \mathrm{C}, 37^{\circ} \mathrm{C}$ \\
Blood agar $(10 \%)$ & $25^{\circ} \mathrm{C}, 33^{\circ} \mathrm{C}, 37^{\circ} \mathrm{C}$ \\
Thioglycollate broth & $25^{\circ} \mathrm{C} .37^{\circ} \mathrm{C}$ \\
Mueller Hinton agar with isovitalex $1 \%$, & $33^{\circ} \mathrm{C}, 37^{\circ} \mathrm{C}$ \\
vancomycin $3 \mathrm{mg} / \mathrm{ml}$, chocolatised horse blood & \\
$(5 \%)$ & \\
Wilkens Chalgren agar & $37^{\circ} \mathrm{C}$ \\
\hline
\end{tabular}

Table 2. Cell-free culture media used for the attempted recovery of $C$. granulomatis

\begin{tabular}{ll}
\hline Medium & $\begin{array}{l}\text { Incubation } \\
\text { temperature }\end{array}$ \\
\hline Dulaneys slants & $25^{\circ} \mathrm{C}, 37^{\circ} \mathrm{C}$ \\
-modified: $50 \%$ egg yolk in thioglycollate medium and thioglycollate overlay & $25^{\circ} \mathrm{C}, 37^{\circ} \mathrm{C}$ \\
-modified: $50 \%$ egg yolk in Lockes solution and thioglycollate overlay & $25^{\circ} \mathrm{C}, 37^{\circ} \mathrm{C}$ \\
-modified: $50 \%$ egg yolk in thioglycollate medium and Lockes solution overlay & $25^{\circ} \mathrm{C}, 37^{\circ} \mathrm{C}$ \\
-modified: 50\% egg yolk in Lockes solution and normal human sera $(1$ in 10$)$ and Lockes & $25^{\circ} \mathrm{C}, 37^{\circ} \mathrm{C}$ \\
$\quad$ solution overlay & $25^{\circ} \mathrm{C}, 37^{\circ} \mathrm{C}$ \\
Lactalbumin hydrolysate (LH) & $25^{\circ} \mathrm{C}, 37^{\circ} \mathrm{C}$ \\
-with sodium azide and with brilliant green & $25^{\circ} \mathrm{C}, 37^{\circ} \mathrm{C}$ \\
-with activated charcoal & $25^{\circ} \mathrm{C}, 37^{\circ} \mathrm{C}$ \\
-LH replaced with phytone peptone & $25^{\circ} \mathrm{C}, 37^{\circ} \mathrm{C}$ \\
-LH replaced with yolk from $5-7$-day embryo & $25^{\circ} \mathrm{C}, 33^{\circ} \mathrm{C}, 37^{\circ} \mathrm{C}$ \\
Embryonic yolk & $25^{\circ} \mathrm{C}, 33^{\circ} \mathrm{C}, 37^{\circ} \mathrm{C}$ \\
-with mascerated chick heart & 16 \\
Cystine agar slants & $25^{\circ} \mathrm{C}, 33^{\circ} \mathrm{C}, 37^{\circ} \mathrm{C}$ \\
\hline
\end{tabular}


various culture media were inoculated and incubated at appropriate temperatures and atmospheric requirements for a period of 7 days. The coverslip from each vial was air-dried, stained by Gram's and rapid Giemsa (RapiDiff) [7] stains and examined by light microscopy at $\times 1000$ magnification. During the development of the culture system, a total of 22 biopsy specimens was subjected to this procedure for co-culture. Pure cultures of $C$. granulomatis were obtained from only three of these specimens and the remaining 19 cultures were overgrown with various micro-organisms, despite amikacin treatment. Twelve of the 19 cultures contained bacteria morphologically resembling C. granulomatis among the mixed cultures.

\section{Transmission electron microscopy}

Cells from the three positive pure co-cultures were scraped off the coverslips. These suspensions were centrifuged at $12000 \mathrm{rpm}$ for $15 \mathrm{~min}$ and the deposits were fixed in glutaraldehyde 1\% in Eagle's minimal essential media with Earle's balanced salts solution (EMEM) (Whittaker M. A. Bioproducts) for $2 \mathrm{~h}$. The specimens were thereafter washed in EMEM and postfixed in osmium tetroxide $1 \%$ in $0.1 \mathrm{M}$ cacodylate buffer for $1 \mathrm{~h}$. The specimens were then dehydrated through ascending grades of alcohol and embedded in araldite epoxy resin. Sections $(50 \mathrm{~nm})$ were cut on a Reichert ultracut microtome and stained with Reynold's lead citrate and uranyl acetate before examination with a Joel $100 \mathrm{C}$ transmission electron microscope.

\section{Modification of the co-culture method}

The co-culture method was modified in three ways: the decontamination procedure for specimens, the source of PBMC and the use of fetal calf serum instead of autologous serum for culture. To establish which antibiotics could be used for specimen decontamination, all contaminating organisms were cultured and tested for their susceptibility to a variety of antimicrobial agents. Thereafter, subsequent biopsy specimens were subjected to a combination of vancomycin (Eli Lilly, USA) $5 \mathrm{mg} / \mathrm{L}$, metronidazole (Rhone-Poulenc) $10 \mathrm{mg} / \mathrm{L}$, and amikacin (Bristol Laboratories) $10 \mathrm{mg} / \mathrm{L}$ for $2 \mathrm{~h}$ and this combination was found to be most appropriate in eliminating bacterial contamination. As a regular supply of blood from laboratory volunteers is difficult to obtain, PBMC isolated from HIV-negative blood donors attending the Natal Blood Transfusion Services were used. Buffy coat fractions were mixed with pre-warmed unsupplemented RPMI 1640 and transported to the laboratory, and immediately subjected to density gradient centrifugation as described above. The autologous serum was replaced with heatinactivated fetal calf serum (Delta Bioproducts, South Africa). This modified method was used for coculturing additional biopsy specimens from female patients and tissue scrapings obtained from patients presenting with genital ulcer disease to the Sexually
Transmitted Diseases (STD) Clinic, City Health, Durban.

\section{Culture from tissue scrapings}

In a study to determine the aetiology of genital ulcer disease amongst adult males, 200 consecutive patients with genital ulceration were investigated. Tissue scrapings were obtained with a $100 \mu \mathrm{l}$ plastic bacteriological loop (Bibby Sterilin) and collected in $500 \mu \mathrm{l}$ of PBS, $\mathrm{pH} 7.2$. One hundred $\mu$ l were transferred to $500 \mu \mathrm{l}$ of decontamination medium containing RPMI 1640 supplemented with fetal calf serum $10 \%$ and amikacin $10 \mathrm{mg} / \mathrm{L}$, vancomycin $5 \mathrm{mg} / \mathrm{L}$ and metronidazole $10 \mathrm{mg} / \mathrm{L}$. After $2 \mathrm{~h}$ the tubes were centrifuged at low speed, excess supernate was discarded and the deposit was resuspended in $1 \mathrm{ml}$ of RPMI 1640 supplemented with fetal calf serum $10 \%$ without antibiotics, before inoculation on to mononuclear cells.

\section{Immunofluorescence}

Slides of all positive co-cultures were incubated for $30 \mathrm{~min}$ at $37^{\circ} \mathrm{C}$ in a humidified chamber with sera from two patients with granuloma inguinale who presented with lesions of 3 months and 1 year duration. Serum from a volunteer with no past or present history of genital ulcer disease was also tested. All sera were tested at dilutions of 1 in 80 and 1 in 160 . The slides were washed and re-incubated with fluorescein isothiocyanate-labelled mouse anti-human IgG (Wellcome Diagnostics) for $30 \mathrm{~min}$. Smears obtained from the ulcerative lesions of patients with granuloma inguinale which showed characteristic 'Donovan bodies' were used as positive controls. Cultures of laboratory strains of Klebsiella pneumoniae, $K$. oxytoca, $K$. aerogenes, Enterobacter cloacae, Citrobacter freundii and Escherichia coli were used as negative controls. Both positive and negative control slides were tested with the patients' sera and serum from the volunteer.

\section{Results}

During development of the co-culture system, pure cultures of $C$. granulomatis were obtained from three of 22 biopsy specimens from women with granuloma inguinale (Donovanosis). An additional biopsy specimen yielded pure growth after use of the modified method. Fourteen of the 200 tissue scrapings from men presenting with genital ulcers to the STD Clinic yielded growth in the monocyte co-culture after incubation for $48 \mathrm{~h}$. None of these grew on any of the cell-free culture media (Table 1) that were incubated for 7 days.

All co-cultures, i.e., the four from biopsy specimens and 14 from tissue scrapings, tested positive in the indirect immunofluorescence test with the patients' sera (Fig. 1A) and negative with the serum from the volunteer at both dilutions. Direct smears from lesions 

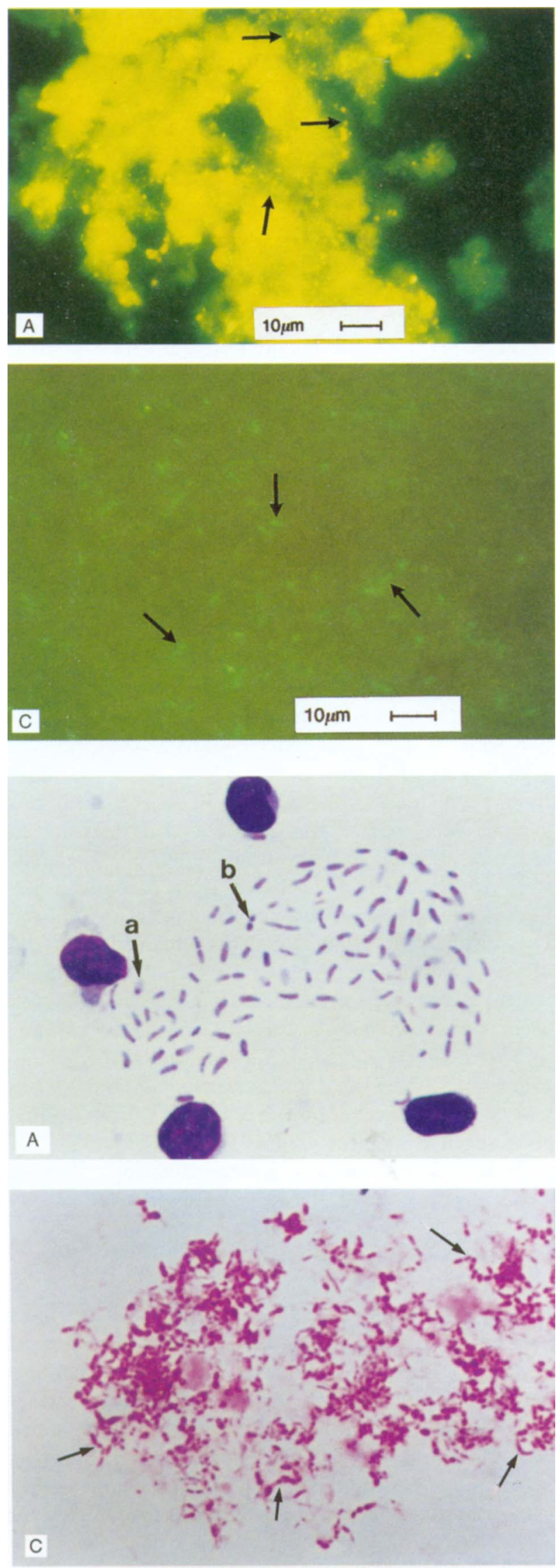

with 'Donovan bodies' were also positive (Fig. 1B) with patients' sera and negative with serum from the volunteer, whilst smears of the control bacterial cultures were negative (Fig. 1C) with both sets of sera.

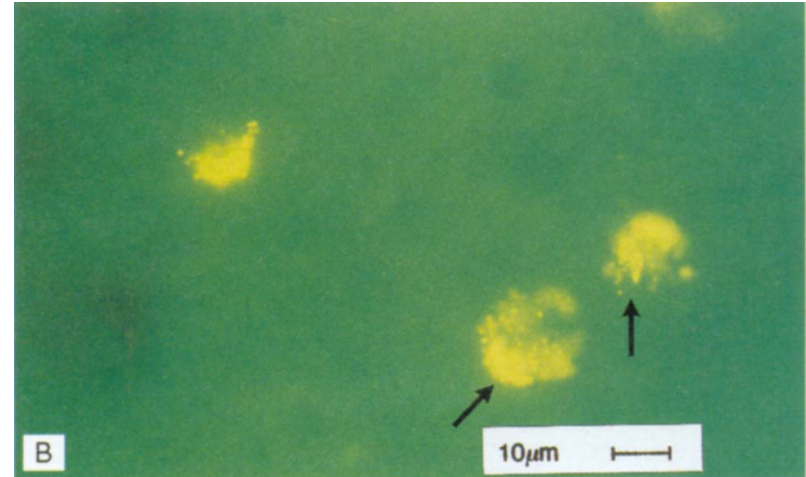

Fig. 1. Photomicrographs of indirect immunofluorescence tests with immune serum from patients with granuloma inguinale. A, Calymmatobacterium granulomatis fluorescing brightly within infected mononuclear cells. B, Intracellular fluorescing 'Donovan' bodies in smears obtained from lesions of granuloma inguinale. C, Absence of fluorescence of bacterial culture of $K$. pneumoniae. Similar results were obtained for $K$. oxytoca, K. aerogenes, Ent. cloacae, C. freundii and $E$. coli.

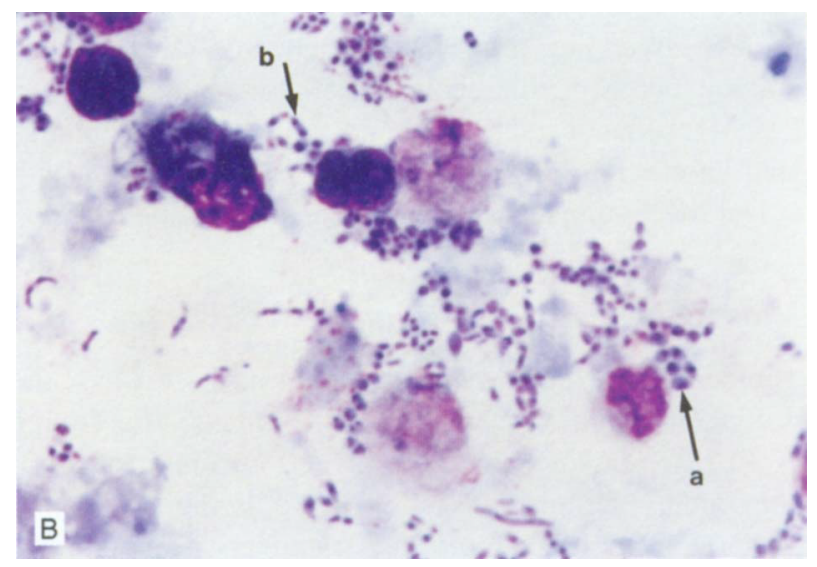

Fig. 2. Photomicrographs of stained preparations of monocyte co-cultures by light microscopy. A, Rapid Giemsa (RapiDiff)-stained smears of infected monocytes after incubation for $48 \mathrm{~h}$ with extracellular organisms displaying pleomorphism with distinct single (a) and bipolar (b) condensation. B, Rapid Giemsa (RapiDiff)stained smears of infected monocytes after several passages with an increase in the number of extracellular, coccobacillary forms with single (a) and bipolar (b) condensation. C, Gram-stained smears of infected monocytes with gram-negative pleomorphic organisms.

The co-cultures remained viable on subculture for at least eight passages. Micro-organisms with the typical morphology of the aetiological bacteria were visualised both intra- and extra-cellularly in co-cultures. 
The extracellular bacteria were in close proximity to the monocytes. The staining reaction revealed characteristic single and bipolar condensation as described for 'Donovan bodies' (Fig. 2A). The bacteria were pleomorphic with either bulging or tapered ends. Dividing bacilli were evident. The size range was $0.5-$ $2.0 \mu \mathrm{m}$ in width and $1.0-2.5 \mu \mathrm{m}$ in length. After subsequent passages an increase in the number of bacterial cells was observed with a number of coccobacillary forms present (Fig. 2B). Around all the cells a translucent area was present, suggestive of capsule formation. The single and bipolar condensation was still evident. Gram's stain of the cultures showed that the bacteria were gram-negative (Fig. 2C), although they stained poorly.

On transmission electron microscopy, bacteria appeared singly or in clusters (Fig. 3A) with a number of extracellular dividing organisms (Fig. 3B). They exhibited a characteristic gram-negative cell wall (Fig. $3 C$ ), consisting of an outer membrane (OM), a middle electron opaque layer (MW) and an inner plasma membrane (IM). The periplasmic space (PS) between the outer and inner membrane was electron lucent. Both plasma and outer membranes were approximately $7.5 \mathrm{~nm}$ thick, each displaying the typical trilaminar nature. The capsule (G) was thick, dense and fuzzy (Fig. 3D). A membrane-like structure (TM) was observed on the periphery of the capsule. The cytoplasm was rich in ribosomes, many of them occurring in aggregates. Electron-dense granules (DG) were prominent (Fig. 3D). Pili (fimbriae) or flagella were not identifiable.

\section{Discussion}

The resurgence of granuloma inguinale in the KwaZulu/Natal region of South Africa prompted this attempt to culture the aetiological agent, $C$. granulomatis. Initial efforts to emulate the work of the early researchers (1940-1960) met with no success. This is also in keeping with the unavailability of the organism from any international type culture collection. However, when the yolk sacs of 5-7-day-old fertile chick eggs were used, the aetiological organism was maintained but could not be subcultured for growth.

The choice of PBMC for culture was based on the visualisation of the causative agent within mononuclear cells of specimens (smears and biopsy) of infected tissue. Such a system allows human monocytes and macrophages to control the growth of microbial pathogens and provides an opportunity to study host-parasite interactions [18]. During the initial phase of the study, PBMC were obtained from a
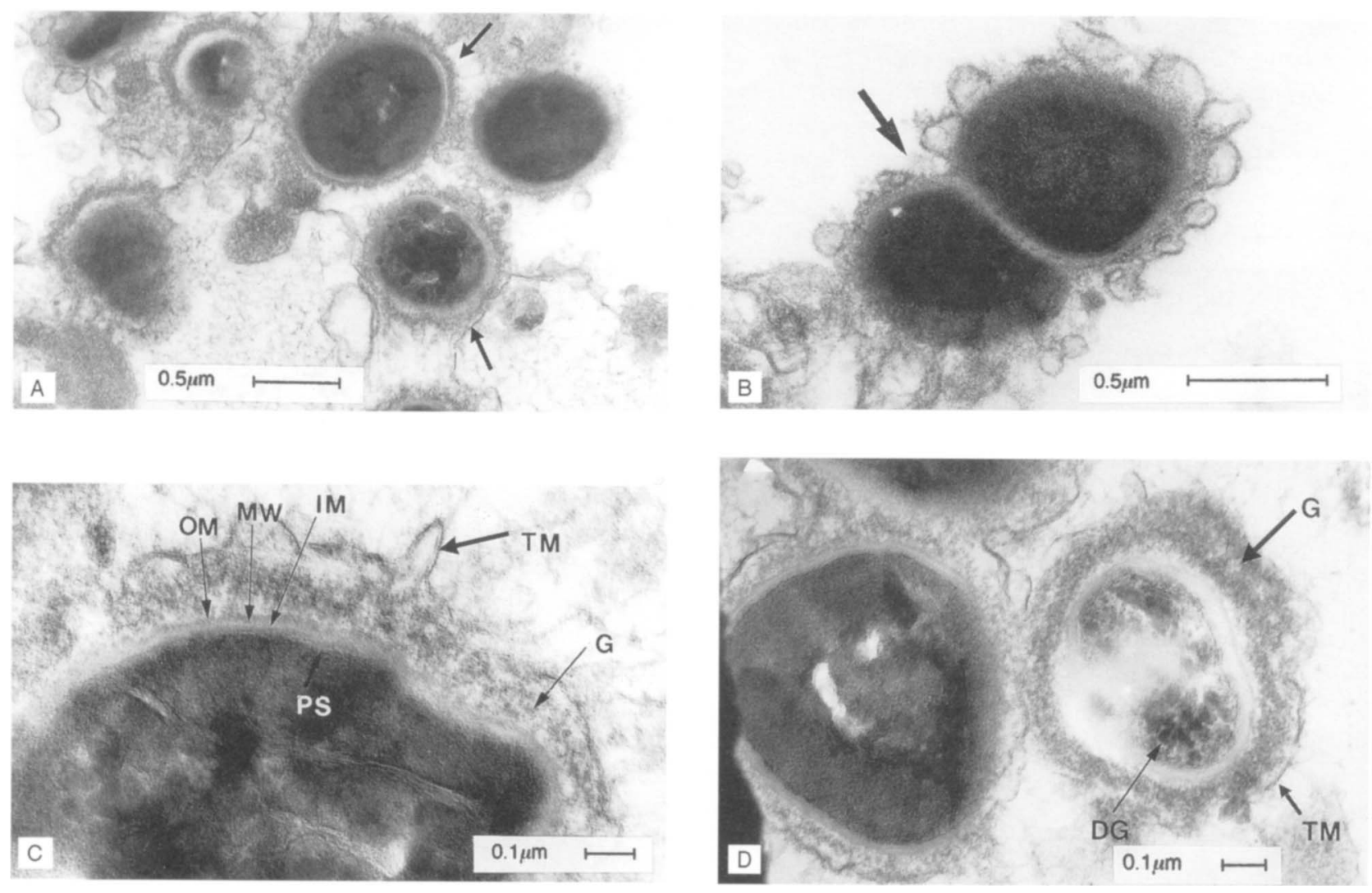

Fig. 3. Electron microscopic characteristics of C. granulomatis from monocyte co-cultures. A, Large number of extracellular organisms. B, Dividing extracellular organisms. C, Gram-negative cell wall structure of the organism consisting of an outer membrane (OM), middle electron opaque layer (MW), inner plasma membrane (IM) with periplasmic space (PS) and evidence of a trilaminar membrane (TM) around the capsule. D, Characteristic thick, fuzzy and electron dense capsule (G) with numerous electron dense granules (DG) within the cytoplasm. 
single donor, a method which proved to be fairly restrictive. The availability of HIV-negative blood donor PBMC from the Natal Blood Transfusion services facilitated the regular supply of these cells. A natural extension of this would be the use of an immortalised monocyte cell line.

A predictable problem of growing organisms from genital site lesions is that of contamination with other less fastidious organisms which overgrow C. granulomatis and kill the PBMC as well. Initial attempts aimed to decontaminate these specimens by the use of an aminoglycoside only. These antibiotics do not enter eukaryotic cells and are, therefore, expected to kill all susceptible extracellular bacteria. This would include all extracellular C. granulomatis, because aminoglycosides have been used for the successful treatment of granuloma inguinale $[1,19]$. However, it was hoped that there would be sufficient numbers of intracellular bacteria to maintain growth of the organism. This approach was successful and the growth of $C$. granulomatis from biopsy specimens of three women with granuloma inguinale was reported [17]. However, in view of the persisting contamination of biopsy specimens with aminoglycoside-resistant gram-positive cocci and anaerobic bacteria, metronidazole and vancomycin were added on the presumption that $C$. granulomatis is not an anaerobic organism. The combination of vancomycin and metronidazole together with amikacin was used for decontamination on additional biopsy specimens and on scrapings of genital ulcers. Successful culture of $C$. granulomatis was obtained in 14 of 200 men with genital ulcer disease from whom ulcer scrapings were collected.

Confirmation that organisms obtained in co-culture were $C$. granulomatis is based on three observations: the isolates did not grow on any of the extensive cellfree culture media listed in Table 2; they demonstrated a positive reaction in the immunofluorescence test with immune sera; and they showed striking morphological similarities with $C$. granulomatis by both light and transmission electron microscopy.

In dirèct smears the 'Donovan bodies' are seen intracytoplasmically within macrophages and are pathognomonic for granuloma inguinale [6]. The bacteria within these cells appear as either definite short coccobacilli or very pleomorphic capsulate forms. It is suggested that the pleomorphic forms are undergoing a process of bacterial elongation and active replication. The pleomorphic nature of the organism in culture has been described by several workers $[9,16,20]$. The bacteria in the monocyte coculture after incubation for $48 \mathrm{~h}$ at $37^{\circ} \mathrm{C}$ in $\mathrm{CO}_{2} 5 \%$ in air were extremely pleomorphic, varying in size and shape in comparison to those usually seen in direct smears, suggesting that these organisms were in a process of cell division and multiplication. The morphology of the bacteria varied after subsequent passages and was either pleomorphic or coccobacillary. During these subsequent passages the capsules and the single or bipolar staining reaction of the organisms were still evident. This morphological variation may result from the demonstration of different stages of growth by viable cultures in an optimal growth environment. Some authors have reported the growth of what they believed to be $C$. granulomatis on cell-free growth media [9, 14-16]. Although this study used all the media reported, no growth was obtained, despite following the published methodology for the preparation of the media. It is possible that unpublished details or unidentifiable differences in the ingredients may be the reason for these negative results. Another explanation could be that previously reported isolates of C. granulomatis which grew on cell-free media belonged to a different species.

Anderson et al. reported the presence of C. granulomatis specific antibodies in convalescent sera of patients with granuloma inguinale [21], whilst others have found similar responses when using Klebsiella antigen instead of Calymmatobacterium antigen $[22,23]$. Although there are controversies regarding cross-reactivity with Klebsiella species in such a test, no reaction was observed with the control organisms, including the three species of Klebsiella. These results confirm the lack of cross-reactivity with other bacterial antigens. All the monocyte co-culture isolates and the direct smears containing 'Donovan bodies' used as positive controls showed bright fluorescence.

Previous reports of the electron microscopic features of $C$. granulomatis have been inconsistent. Davis et al. [24] described the presence of 'bacteriophage' attached to the cell wall and empty phage heads within the organism and it was suggested $C$. granulomatis is a phage modified bacterium. This phenomenon was confirmed by Davis in a later study [25], but was strongly refuted by Kuberski et al. [26]. In the present study there was no evidence of particles either within or on the micro-organism to suggest the presence of bacteriophage. Distinct electron dense granules were evident within the bacterial body and these would give the organism the characteristic single or bipolar 'safety pin' appearance.

The presence of the capsule has also been described and confirmed [24-26]. However, the description appears to be discrepant in relation to the present study. Both authors [24,26] described the capsule as an electron lucent area around the organism, whereas the feature of the capsule in the present study was electron dense. The capsule characteristics have been described extensively for other bacterial species and invariably have an electron dense appearance [27]. One explanation could be that as previous electron microscopic studies have been performed directly on clinical biopsy specimens, it is possible that these 
electron lucent areas are in reality intracellular vacuoles in which the bacteria are situated and not bacterial capsules. In the present study, electron microscopic features are described from cultured specimens and not from biopsy specimens. Davis et al. [24] suggested that the capsule is unusual as it is large in size and has a capsular membrane. Whether the membrane-like structure observed on the periphery of the capsule in this study represents the capsular membrane seen in Davis' study is unclear. Clearly there was no evidence of pili (fimbriae) or flagella as suggested by Chandra et al. [28]. The bacterial cell wall was characteristically that of a gram-negative bacterium as desribed by others $[24,26]$.

This study developed a culture method for $C$. granulomatis which can be applied to routine clinical specimens such as ulcer scrapings, as well as biopsy samples of large lesions. The successful culture of the aetiological agent of granuloma inguinale will enable the collection of a sufficient number of bacterial strains to study the biological characteristics and virulence attributes of this micro-organism, to determine its antimicrobial susceptibility profile and to develop a definitive diagnostic test. This will lead to a better understanding of the epidemiology and pathogenesis of this disease.

This study was supported by grants from the University of Natal research fund and the Medical Research Council of South Africa.

\section{References}

1. Richens J. The diagnosis and treatment of donovanosis (granuloma inguinale). Genitourin Med 1991; 67, 441-452. ,

2. Bassa AGH, Hoosen AA, Moodley J, Bramdev A. Granuloma inguinale (donovanosis) in women. An analysis of 61 cases from Durban, South Africa. Sex Transm Dis 1993; 20: $164-167$.

3. Donovan C. Medical cases from Madras General Hospital. Indian Medical Gazette 1905; 40: 411-414.

4. Aragão HD, Vianna G. Pesquizas sobre o granuloma venereo. Mem Inst Oswaldo Cruz 1913; 5: 211-238.

5. Cannefax GR. The technic of the tissue spread method for demonstrating Donovan bodies. J Ven Dis Inform 1948; 29: 201-204.

6. Greenblatt RB, Barfield WE. Newer methods in the diagnosis and treatment of granuloma inguinale. Br J Ven Dis 1952; 28: $123-128$.

7. O'Farrell N, Hoosen AA, Coetzee K, van den Ende J. A rapid stain for the diagnosis of granuloma inguinale. Genitourin Med 1990; 66: 200-201.

8. Anderson $\mathrm{K}$. The cultivation from granuloma inguinale of a microorganism having the characteristics of Donovan bodies in the yolk sac of chick embryos. Science 1943; 97: 560-561.

9. Anderson K, DeMonbreun WA, Goodpasture EW. An etiologic consideration of Donovania granulomatis cultivated from granuloma inguinale (three cases) in embryonic yolk. $J$ Exp Med 1945; 81: 25-39.

10. Sheldon WH, Thebaut BR, Heyman A, Wall MJ. Osteomyelitis caused by granuloma inguinale. Report of a case with cultivation of the Donovan body in yolk sack of the developing chick embryo. Am J Med Sci 1945; 210: 237-245.

11. Beveridge WIB. The action of antimony and some other bacteriostatic substances on Donovania granulomatis isolated in the chick embryo. J Immunol 1946; 53: 215-223.

12. Dienst RB, Greenblatt RB, Chen $\mathrm{CH}$. Laboratory diagnosis of granuloma inguinale and studies on the cultivation of the Donovan body. Am J Syph Gonor Ven Dis 1948; 32: 301-306.

13. Thomison JB. Primary isolation of Donovania granulomatis by chick brain inoculation, and induction of cerebral miliary granulomata. Proc Soc Exp Biol Med 1951; 77: 557-558.

14. Dulaney AD, Guo K, Packer H. Donovania granulomatis: cultivation, antigen preparation, and immunological tests. $J$ Immunol 1948; 59: 335-340.

15. Goldberg J. Studies on granuloma inguinale. IV. Growth requirements of Donovania granulomatis and its relationship to the natural habitat of the organism. Br J Ven Dis 1959; 35: $266-268$.

16. Goldberg J. Studies on granuloma inguinale. V. Isolation of a bacterium resembling Donovania granulomatis from the faeces of a patient with granuloma inguinale. $\mathrm{Br} J$ Ven Dis 1962; 38: 99-102.

17. Kharsany ABM, Hoosen AA, Kiepiela P, Naicker T, Sturm AW. Culture of Calymmatobacterium granulomatis. Clin Infect Dis 1996; 22: 391.

18. Carvalho de Sousa JP, Rastogi N. Comparative ability of human monocytes and macrophages to control the intracellular growth of Mycobacterium avium and Mycobacterium tuberculosis: effect of interferon-gamma and indomethacin. FEMS Microbiol Immunol 1992; 4: 329-334.

19. Hoosen AA, Mphatsoe M, Kharsany ABM, Moodley J, Bassa A, Bramdev A. Granuloma inguinale in association with pregnancy and HIV infection. Int J Gynaecol Obstet 1996; 53: $133-138$.

20. Rake G, Oskay JJ. Cultural characteristics of Donovania granulomatis. J Bacteriol 1948; 55: 667-675.

21. Anderson K, Goodpasture EW, DeMonbreun WA. Immunologic relationship of Donovania granulomatis to granuloma inguinale. $J$ Exp Med 1945; 81: 41-50.

22. Rake G. The antigenic relationships of Donovania granulomatis (Anderson) and the significance of this organism in granuloma inguinale. Am J Syph Gonor Ven Dis 1948; 32: $150-158$.

23. Packer H, Goldberg J. Complement fixation studies in granuloma inguinale. Am J Trop Med Hyg 1950; 30: 387-395.

24. Davis CM, Usaf MC, Collins C. Granuloma inguinale: an ultrastructural study of Calymmatobacterium granulomatis. $J$ Invest Dermatol 1969; 53: 315-321.

25. Davis CM. Granuloma inguinale. A clinical, histological, and ultrastructural study. JAMA 1970; 211: 632-636.

26. Kuberski T, Papadimitriou JM, Phillips P. Ultrastructure of Calymmatobacterium granulomatis in lesions of granuloma inguinale. J Infect Dis 1980; 142: 744-749.

27. Costerton JW. The role of electron microscopy in the elucidation of bacterial structure and function. Annu Rev Microbiol 1979; 33: 459-479.

28. Chandra M, Jain AK, Ganguly DD, Sharma AK, Bhargava NC. An ultrastructural study of donovanosis. Indian $J$ Med Res 1989; 89: 158-164. 